\title{
Supplementary figures for
}

"Evidence of Polaron Excitations in Low Temperature Raman Spectra of Oxalic Acid Dihydrate”

Vlasta Mohaček-Grošev, ${ }^{\text {a,b }}$ Jože Grdadolnikc and Dušan Hadžid

a Ruđer Bošković Institute, Bijenička cesta 54, 10002 Zagreb, Croatia, mohacek@irb.hr

b Center of Excellence for Advanced Materials and Sensing Devices, Ruđer Bošković Institute, Bijenička c. 54, Zagreb, Croatia

c National Institute of Chemistry, Hajdrihova 19, 1000 Ljubljana, Slovenia, joze.grdadolnik@ki.si

d National Institute of Chemistry, Hajdrihova 19, 1000 Ljubljana, Slovenia, dusan.hadzi@ki.si 
S1 Raman spectra of oxalic acid dihydrate in $y(z y) x$ polarization.

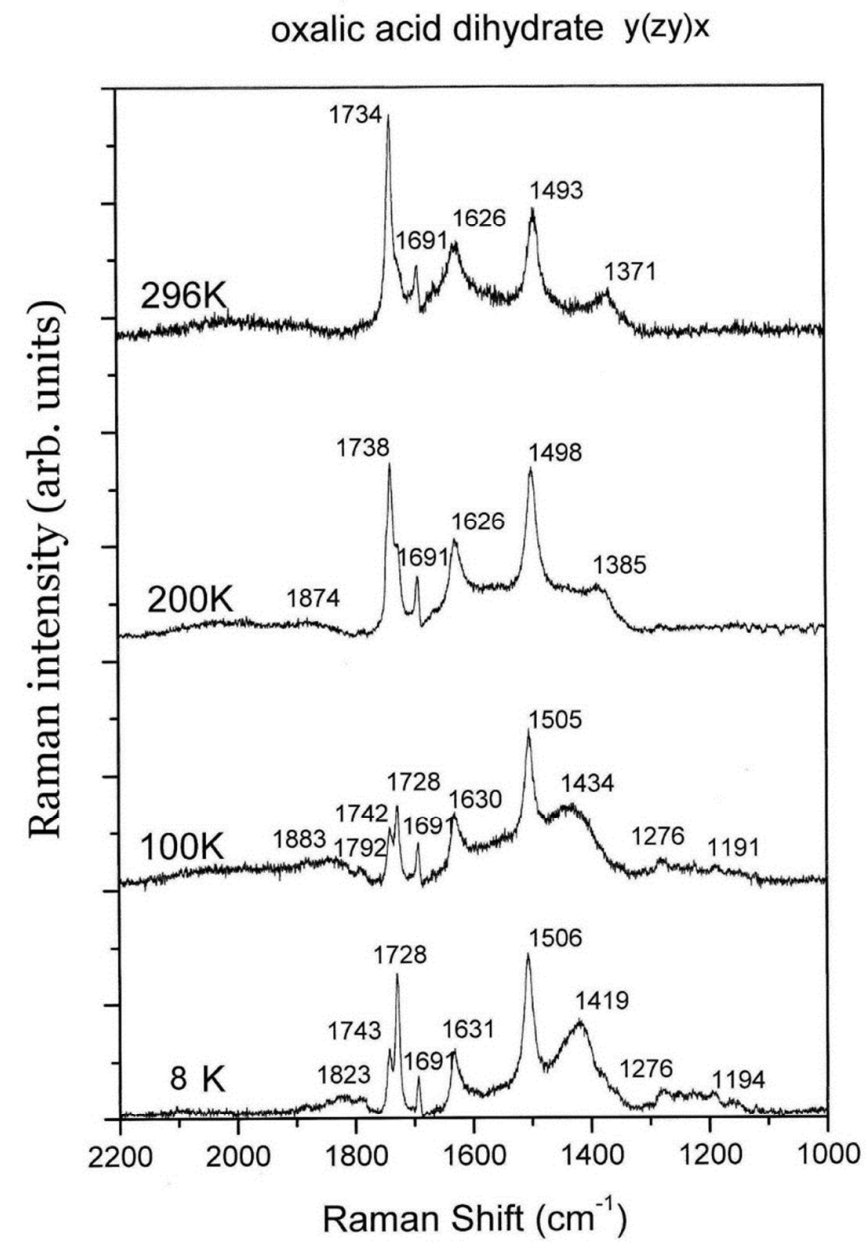


S2a Raman spectra of deuterated oxalic acid dihydrate in $\mathrm{y}(\mathrm{zz}) \mathrm{x}$ polarization.

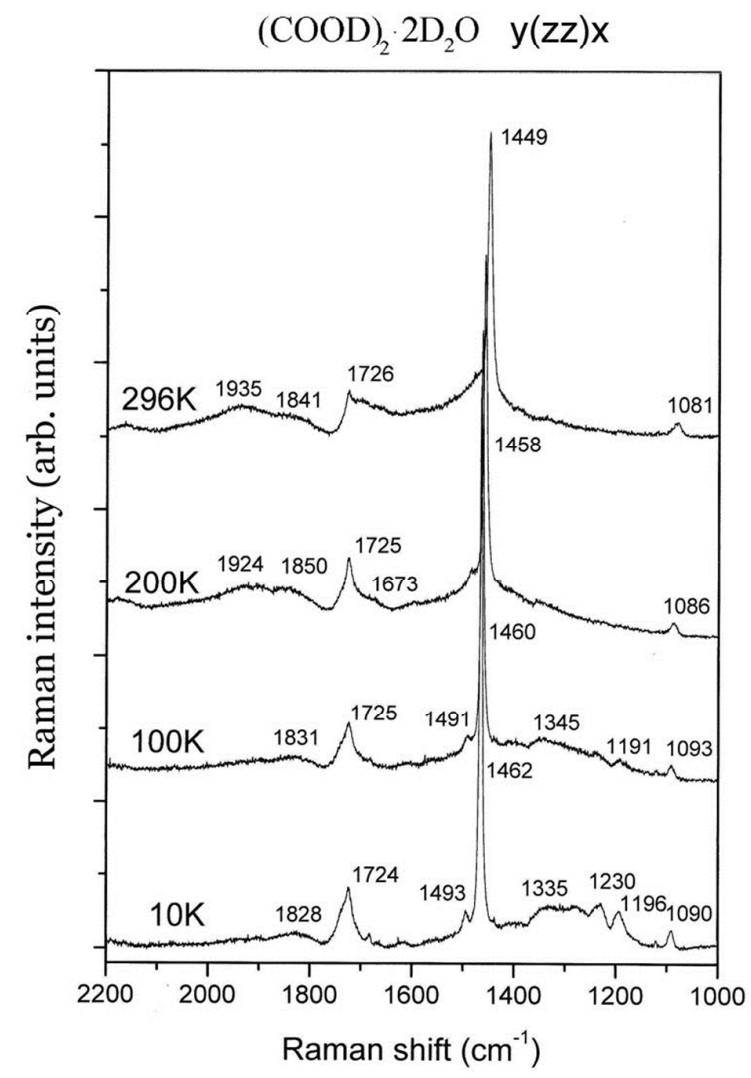


S2b Raman spectra of deuterated oxalic acid dihydrate in $\mathrm{y}(\mathrm{zy}) \mathrm{x}$ polarization.

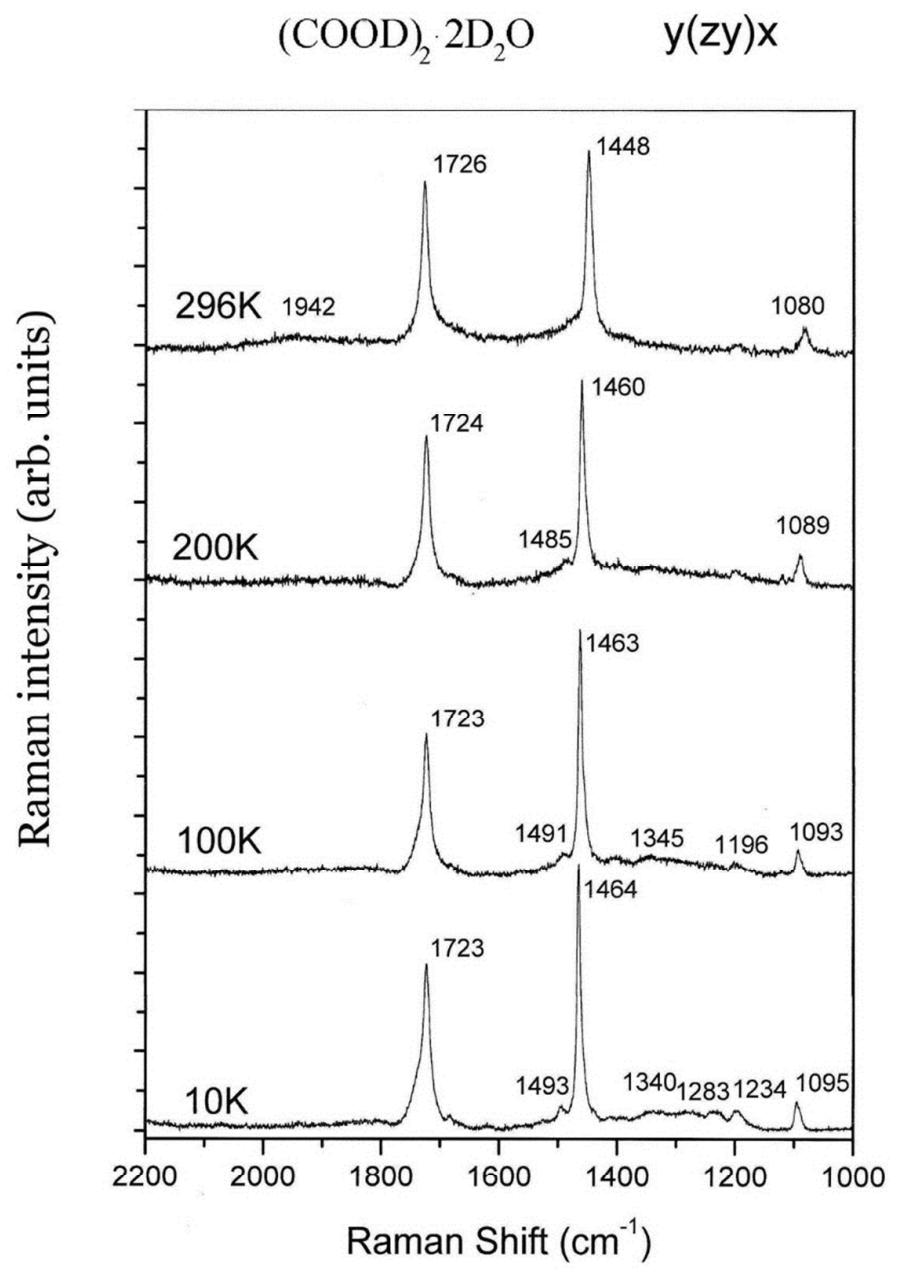

